\title{
Nigerian English: Identifying Semantic Features As Variety Markers
}

\author{
Kaan, Aondover Theophilus; Amase, Emmanuel Lanior ( $\mathrm{PhD})$; \\ Tsavmbu, Alexis Aondover \\ Department Of English, Federal University Dutsin-Ma, Katsina State.
}

\begin{abstract}
In this paper, the authors examine Nigerian English in the light of its unique characteristics emanating from the mode of acquisition of the language by Nigerians, and the socio-cultural environment in which English is now used. Using Uriel Weinreich's theory of language contact to explicate the phenomenon of language variation, they observe that the English language in Nigeria has been cultivated and re-domesticated as well as indigenized to accommodate the culture and tradition of the people and as such, has acquired local colour and distinguished itself from the native speaker variety with features reflected at the semantic level. The paper identifies meaning narrowing, semantic extension, semantic reduplication, semantic shift, coinage of new words with new meanings, the Nigerianisation of idioms and proverbs, ambiguity resulting from omission of articles among other semantic issues as marking off the Nigerian English and posing a challenge to the notions of international intelligibility and acceptability.
\end{abstract}

Key words: Nigerian English, Semantic Features, Variety Markers, Intelligibility, Acceptability.

... I feel that the English language will be able to carry the weight of my African experience. But it will have to be a new English, still in full communion with its ancestral home but altered to suit its new African surrounding.

- Chinua Achebe

\section{Introduction}

The English language in Nigeria is in the outer concentric circle, a frame work produced by Kachru (1986) for conceptualizing English as a world language. It is in its second language status where it is used for official purposes and for communication between different language groups. This is the status of the English language in countries like Singapore, Malaysia, India, Tanzania, Zimbabwe, Zambia, Ghana etc. which fell under British colonization, quite contrasted from the situation of English language in the United Kingdom, the United States of America, Australia, New Zealand and South Africa (the inner circle), where English is used as a first language and a nativized code and with noticeable environmental differences from what is obtainable in the second language variety.

In Nigeria, we have often heard people talk about a "Nigerian English" and according to Ogu, J.N. (1992), Walsh, N.G. (1967) was among the first to draw attention to the existence of a variety of English language known as "Nigerian English". Ogu quoted Walsh as saying that:

The varieties of English spoken by educated Nigerians, no matter what their language, have enough features in common to mark off a general type, which may be called Nigerian English (1992:88).

Since then, scholars and linguists of repute have endorsed their stamp on it as a legitimate variety and a sociolinguistic reality (cf spencer, ed., 1971; Ubahakwe, ed., 1979; Pride, ed., 1982; Kachru, ed., 1983; Platt, et al, 1984, Jowitt, 1991; Bamgbose, et al 1995; Munzali, 1979; Adetugbo, 1979) and have shifted their concerns to issues of its identification and characterization. It is not in any way a derogatory term and one characterized by errors and non-standard forms as language purists tend to view it, neither is it one of an inferior status to others like British, American, Canadian, Australian, New Zealandan English.

The English language in Nigeria has undergone "domestication" (Achebe, 1975), "localization" (Kachru, B., 1983), and "Nativization" (Odumuh, 1993). These nomenclatures are central to explaining the fact that English has come to stay with us in all our endeavors and we are in the process of transferring, planting and developing the language in a non-native environment. Thus in Achebe's view, we should bend the language to accommodate our thought patterns and perform tasks suitable to us instead of looking at it as the language of the colonizers. 
After so many years of the implantation of English on the Nigerian soil, and the fact that a large number of Nigerians have grown up to understand English not so much again as the language of the colonizer, but as a language in which virtually all the school subjects are taught, and as a language in use across the length and breadth of the country, it will seem really strange and unjust if English should continue to be seen as a 'foreign' language in our midst. Ashiko (2002) has shown concerns to this when he rightly observes that:

... There are Nigerians now for whom English is the language which allows them to express themselves the way no other language does. Their sensibilities, their thought processes, their instinctive verbal responses are canalized through English.

It is a linguistic fact that quite a number of young Nigerians born and bred in this country can claim English as their mother tongue according to this definition:

Mother tongue can also be defined, as the language in which a bi-

or multilingual person conducts his everyday activities and in

which he/she has the greatest linguistic facility or intuitive

knowledge (Akindele and Adegbite 1992:39-40).

However, the English language that the colonial masters bequeathed to us and which the native speakers use is not exactly the same English as we in Nigeria use. Though there are certain "common core" features running through these varieties as there are a set of grammatical and other characteristic features that are common to both the native-speaker variety and the Nigerian variety of English, ours is a variety that is different in a number of features. These differential features of Nigerian English may be phonological, syntactic, lexical, semantic and pragmatic in import. This paper isolates the semantic level of language as the one that is most susceptible to creativity as English is used in Nigeria. It is in this component that the influence of the local languages, the socio-cultural as well as the physical Nigerian environment is strongly reflected and referred to as "local colour".

The theoretical pivot of the phenomenon that produced Nigerian English is that of language contact and variation. Uriel Weinreich (1968) who could be regarded as the 'father' of modern day contact linguistics presented a systematic framework for the categorization of the mutual influence and 'mixing' that take place when languages come in contact. Since then, several linguists have observed and analyzed this phenomenon in different parts of the world.

Each of the new Englishes has distinct characteristics, as well as distinct linguistic and cultural identities largely due to the different historical, geographical, political and social-cultural factors that gave birth to them. Thus Nigerian English will differ from either Ghanaian or Indian English with the depth of impact at the various linguistic levels determined by the degree of localization of English.

\section{Semantic Identifiers in the Nigerian English}

Because there are bound to be deviations for such a language that travels across shores and functions in virtually every continent of the world, the English language in Nigeria is not spared as it exhibits traits of the Nigerian environment at the semantic level. The semantic components of Nigerian English consist of semantic extension, semantic narrowing, semantic shift, semantic reduplication, and coinage of new words with entirely new meanings (neologisms), the Nigerianization of idioms and proverbs, ambiguity resulting from omission of articles among other semantic issues.

A study of these semantic features will reveal interestingly certain peculiarities, and the linguist studying Nigerian English is at once confronted with the pertinent but often elusive task of identifying, isolating and accounting for this linguistic phenomenon that contributes in marking off the Nigerian English in everyday usage.

\section{Semantic Extension}

Often in Nigerian English, there is the extension of the semantic boundaries of existing English words to cover strange meanings, what Akindele and Adegbite (1992:55) refer to as "the addition of meanings to a standard English word". Typical examples of semantic extension in the English usage in Nigeria could be found in the examples:

1. I gave the police man kola nut (bribe) before I was released.

2. He has a stranger (visitor) this evening.

3. I stayed (lived) in Katsina for two years.

4. Musa hears (understands) English language very well. 
The highlighted words 'kola nut,' 'stranger,' 'stayed' and 'hears' each maintain their Standard English meanings but also acquire additional ones. 'kola nut' refers to the seed of a tree that can be chewed but is extended to mean 'bribe'; 'stranger' which refers to a person you don't know is extended to mean 'visitor'; 'stayed' which implies being in a place for a period of time without moving away is widened to mean 'lived'; ' hears' is expanded to mean 'understands'.

\section{Semantic Narrowing} in:

Meaning of existing English words are semantically narrowed to have a contracted scope as we can see

5. Kerosene is more expensive than fuel (petrol).

6. The family has a boy, now they are expecting a baby (baby girl).

7. My globe (electric bulb) shines brighter than yours.

Thus 'fuel' is narrowed to mean 'petrol'; 'baby' to mean 'baby girl' while 'globe' is contracted to mean 'electric bulb'.

\section{Semantic Shift}

This involves redefining the characteristic pattern of a word within the semantic field and by doing so; the central context of the word becomes marginalized, as in the example:

8. His machine broke down (machine for motorcycle) (Akindele and Adegbite, 1992).

9. PHCN took the light in Sokoto (light for electric power source)

\section{Semantic Reduplication}

Many everyday Nigerian English expressions contain unnecessary repetitions of the same idea. This phenomenon is referred to as tautology -saying the same thing more than once without making one's meaning clearer. Expressions such as:

Repeat what you said again

10. That is my personal opinion

11. Nigeria's past history is worth studying

contain tautology, with the redundant portions highlighted. The Language user is usually not aware of the repetition.

\section{Loans and Coinages with New Meanings}

Some words that have their origins from Nigerian languages are now used as loan words with their meanings from the Nigerian languages transferred into the Nigerian English usage. Such words are commonly used when the English substitutes cannot be readily identified. This can be found in the titles of traditional rulers like 'Emir,' 'Obi,' 'Tor', among others, and they function in standard writings with prepositions to denote the ruler's domain as in 'Sultan of Sokoto', 'Emir of Kano', 'Oni of Ife', etc.

Transfers from Nigerian languages are found in the areas of clothing such as: 'Agbada', 'Babanriga' which is worn as a national dress on formal occasions in Nigeria. It is also referred to as flowing gown, which in itself is a coinage. In the area of indigenous food, the desire to patronize local dishes in homes and in five-star hotels has encouraged the use of local words for food stuff such as 'akara', 'eba', 'tuwo', 'amala', 'ogbono', 'ewedu', etc. All these and many others are transferred from the local languages with semantic import into Nigerian English.

Besides these loans, there are coinages from existing English words with new meanings created. A few of the Nigerian English coinages are 'talking-drum', 'long-leg' 'high life music', 'tight-friend, ' 'go-slow', 'inpregnate', 'head-tie' etc.

\section{Nigerianisation of Idioms and Proverbs}

There is the Nigerianisation of certain idioms and proverbs that have become predominantly the character of Nigerian English. This, perhaps changes the meaning of such idioms and proverbs from standard British English as they are used in the Nigerian environment. For instance,

14. 'Cut your coat according to your size'

(For British English cut your coat according to your cloth);

15. 'One tree cannot make a forest'

(For British English one swallow does not make a summer).

Other socio-culturally influenced words that take the form of idioms include "I will declare surplus" for "I will spend lavishly"; 
"wash your car" to mean "celebrate with one for the purchase of a car"; a woman "taking-in" to mean "pregnant," "to put sand in one's garri" to mean "to thwart one's efforts", to say something "off head" to mean "by heart/off by heart".

\section{Ambiguity}

Ambiguity is an inherent feature of the Nigerian English meaning system. It results from the total or partial failure of elements of language to signal the exact and / or intended meaning by the writer or speaker. Most often than not, the syntactic structure of the Nigerian English accounts for such ambiguity since function words are omitted, thus making an expression ambiguous. For instance, the expressions:

16. Sheep talk at Lagos conference,

17. School demands change

are ambiguous and can only become clear and disambiguated in:

18. A sheep talked at the Lagos conference

or

i. Sheep was talked about (discussed) at the Lagos conference

19. i. The school demands (asks for/requires) a change

ii. The demands (requirements) of the school changed.

The omission of the article ' $a$ ' in 16 and the determiner 'the' in 17 brings about the ambiguity in the above sentences, and this is typical of the semantic character of Nigerian English.

\section{Implications for Intelligibility and Acceptability}

In the face of these semantic variation and deviations that mark off the Nigerian variety of English, there arise the challenges of intelligibility and acceptability of the Nigerian English. The challenge is often compounded when we use "exoglossic"/foreign standards as parameters for determining the intelligibility and acceptability or otherwise of our variety of English.

While native English speaking nations have national standards of English as birthright, most non-native English speaking nations are yet to evolve their own authentic standard variety of the language. Even then, educated opinion on language usage would no doubt, admit that the concept of 'standard' is not based on 'better and worse' but on 'acceptability and non acceptability' (Ubahakwe 1979). Such an acceptability/non acceptability is determined and regulated by the specific speech community in question.

Most characterizations of Nigerian English have rather proceeded to describe the variety in terms of native English usage with the goal of language considered to be "native grammatical competence" (Adetugbo, 1979). The impression made by such description is that the structure of Nigerian English must be evaluated visà-vis the structure of native English or else it will not be acceptable.

... Should we not worry first about acceptability, especially of the spoken medium, within our immediate language environment before we set the too high a goal of international acceptability? (Adetugbo, 1979).

It is out of place to import a standard for measuring Nigerian English from outside because the standard of the variety is derived from within the socio-cultural context but this is not necessarily so mutually exclusive with the world standard as to impede international intelligibility.

Nigerian English is indigenous to Nigeria and its most basic usage is intra-national, a role it plays very well. In terms of international intelligibility, standard Nigerian English is to a large extent intelligible and whatever difficulties encountered along these lines, are not peculiar to Nigerian English, but also to the users of all other varieties of English language worldwide. The difficulties encountered by Nigerian English speakers communicating with American English speakers may be similar in much respect to those encountered by an Australian English speaker communicating with a New Zealander.

Nigerian English does not have a full acceptance among Nigerians. One obvious non linguistic reason attached to this unfavourable attitude is the activities of purists who opine that the recognition of a Nigerian English might spell doom for English Language in Nigeria. But even then, there are enough linguistic data to prove the existence of a localized and acculturated form of English Language as has been pointed out earlier in this paper. Not minding the arguments of purists, however more and more people are beginning to recognize and to have a positive attitude towards Nigerian English. (Adekunle, 1985:36,38) reveals that:

The English language has, as a result of many years of active use in the Nigerian speech community...become part of Nigerian's contemporary environment and behaviours... It is an artifact whose foreign derived components have in the process of its evolution combined with native Nigerian elements to make it local. 
It is pertinent to point out poignantly here that, to sacrifice Nigerian English on the altar of foreign standards of intelligibility and acceptance will amount to under mining the variety and/or total denial of the vital role which the variety plays in the Nigerian social cultural environment.

\section{Conclusion}

In this paper, we have demonstrated that semantic variation has been a pervasive characteristic of the Nigerian variety of English which has been cultivated and nativized to accommodate the culture and traditions of the people. A wide range of semantic features of the Nigerian English have been investigated and it has been proved that these semantic features mark off the variety from other varieties. The paper also argued that the challenges of intelligibility and acceptability could be overcome by looking inwards for a standard Nigerian English, more so that Nigerian English still shares a common core of aspects of World English at different levels of the language, capable of enhancing international intelligibility.

\section{References}

[1]. Achebe, C. (1975). Morning, Yet on Creation Day: A Collection of Essays. London: Heinemann.

[2]. Adekunle, M., (1985). The English Language in Nigeria as a Modern Nigerian Artifact. Jos, Nigeria: Univeristy of Jos Press.

[3]. Adetugbo, A. (1979). "Nigerian English and communicative competence" in Ubahakwe, ed. Varieties and Functions of English language in Nigeria._Ibadan: African UP.

[4]. Ajani, T. (2007). "Is There Indeed A Nigerian English?” in Journal of Humanities and Social Sciences Vol.1 issue 1.

[5]. Akindele, F. and Adegbite, W. (1992). The Sociology and Politics of English Language In Nigeria: An Introduction. Ile-ife: DebiyiIwa.

[6]. Ashiko, J. (2002). "Language and Democracy in Nigeria” in Angya, C. ed., Makurdi Journal of Arts and Culture Vol.3.

[7]. Bamgbose, A, Banjo, A., \& Thomas, A., (1995). New Englishes: A West African Perspective. Ibadan: Mousro/British Council.

[8]. Jibril, M. (1979). "Regional Variation in Nigerian Spoken English" in Ubahakwe, ed. Varieties and Functions of English in Nigeria. Ibadan: African UP.

[9]. Jowitt, D. (1991). Nigerian English Usage: An Intoduction. Ikeja: Longman.

[10]. Kachru, B. ed. (1982). The Other Tongue: English Across Cultures. Oxford: Pergamon. The Spread, Functions And Models of Non-Native Englishes. Oxford: pergamon Press , (1986). The Alchemy of English:

[11]. Odumuh, E. (1983). Sociolinguistics and Nigerian English, Lagos: Sambookman.

[12]. Ogu, J. (1992). A Historical Survey of English and the Nigerian Situation. Lagos: Krafts Books ltd.

[13]. Platt, J., Weber and Ho, M.L (1984). The New Englishes. London: Routledge and Kegan Paul.

[14]. Pride, J.B, ed. (1982).New Englishes. Massachusttes: Newbary House.

[15]. Spencer, J. ed. (1971). The English language in West Africa London: Longman.

[16]. Ubahakwe, E. ed. (1979). Varieties and functions of English Language in Nigeria. Ibadan: African University Press.

[17]. Walsh, N. (1967) "Distinguishing Types and varieties of English in Nigeria". Journal of the Nigerian English studies association. $2: 2,47-55$.

[18]. Weinreich, U. (1968) Languages in Contact: Findings and Problems. The Hague: Mouton. 